\title{
Rhinoscleroma: report of 2 cases and literature review*
}

\author{
Moustapha Ndiaye', Mame Sanou Diouf², Ciré Ndiaye', Abdou Sy³, Malick \\ Ndiaye $^{3}$, Abdourahmane Tall' ${ }^{1}$ Evelyne Siga Diom ${ }^{4}$ Issa Cheikh Ndiaye', \\ Raymond Diouf 2
}

Rhinology Online, Vol 2: 115 - 118, 2019

http://doi.org/10.4193/RHINOL/19.032

*Received for publication:

September 16, 2019

Accepted: November 9, 2019

Published: November 12, 2019

\begin{abstract}
Background: Rhinoscleroma is a chronic and specific granulomatous infectious disease caused by enterobacteria of the family Klebsiella: "Klebsiella rhinoscleromatis"; it reaches the nasal cavities in 95\% of cases. The objective of our study is to report the clinical, diagnostic and therapeutic aspects of our patients.
\end{abstract}

Observations/Medical findings: The study took place at the ENT department of the Fann National University Hospital Center in Dakar, and it was based on two female subjects who are 26 and 60 years old, respectively. The medical examination of the subjects indicated a granulomatous lesion blocking the two nasal cavities. A biopsy performed on each patient revealed a rhinoscleroma. Both patients received doxycycline-based medical treatment with endoscopic endonasal surgery like "Debulking." The patients all recovered nasal breathing after airway clearance. However, we noted a scar retraction of the nasal cavities in the first patient.

Conclusions: As the disease recurs, rhinoscleroma is becoming more and more a cosmopolitan affection. The diagnosis is histological. Well-conducted medical treatment allows healing in early forms while surgery is complementary in advanced forms. The fear of a recurrence calls for an extended follow-up.

Key words: rhinoscleroma, endonasal surgery, Dakar

\section{Introduction}

Rhinoscleroma or more precisely, scleroma is an infectious attack of the respiratory tract due to an enterobacterium called Klebsiella rhinoscleromatis ${ }^{(1)}$. Nasal involvement is initial and almost constant. All pharyngeal, laryngo-tracheobronchial and oral routes may be affected ${ }^{(1,2)}$. After sharing the two clinical cases, and by drawing from the literature review, we will discuss the epidemiological, diagnostic, and therapeutic aspects of this pathology.

\section{Case I}

This case is about a 60-year-old low-income lady with a track record of undocumented thyroidectomy 20 years ago. She was consulted in 2016 for a bilateral epistaxis evolving since 2001. Nasal deformity occurred 6 months later, and nasal pain ap- peared 8 days before admission.

On examination, the patient had a large, indurated nose associated with the presence of nasal fossae filling with granulomatous tissue (Figure 1). The rest of the ENT examination was normal. Histological examination on biopsy samples revealed rhinoscleroma: ulcerated squamous mucous replaced by a polymorphous granulation tissue. The chorion is the seat of Mikulicz cells (Figure 2). No cultures were performed. A computed tomography scan showed obstructive and filled-up tissue of the nasal cavities (Figure 3). The sinuses were free. The treatment consisted of an endoscopic nasal removal of the "debulking" type with the placement of a radiological film in each nasal cavity on either side of the nasal septum. At the end of the procedure, the nasal cavities were filled with a compress soaked with antibiotic ointment; the locks were removed on day 2 of the post-intervention. X-ray 


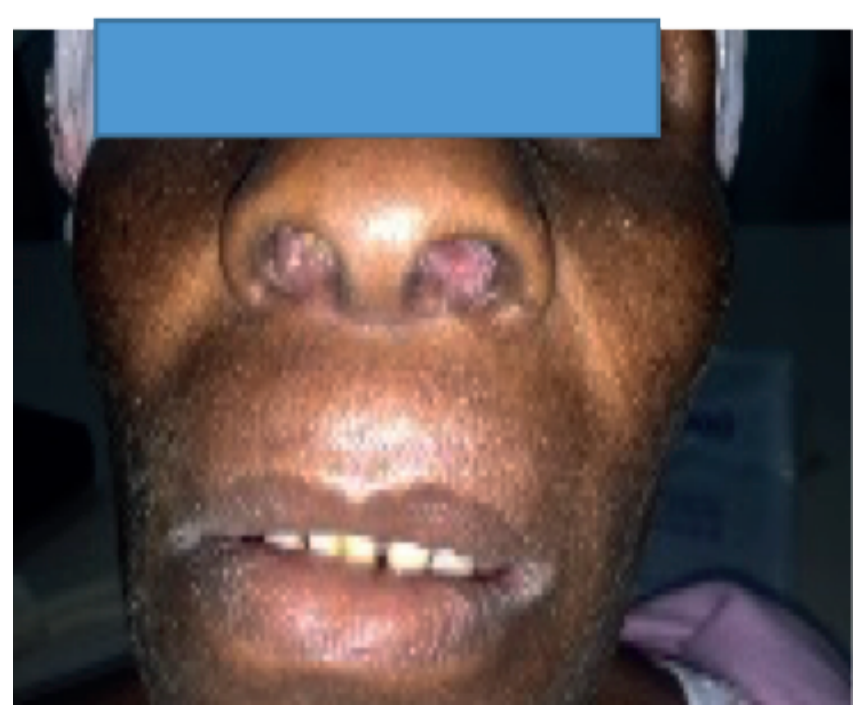

Figure 1. Large indurated nose.

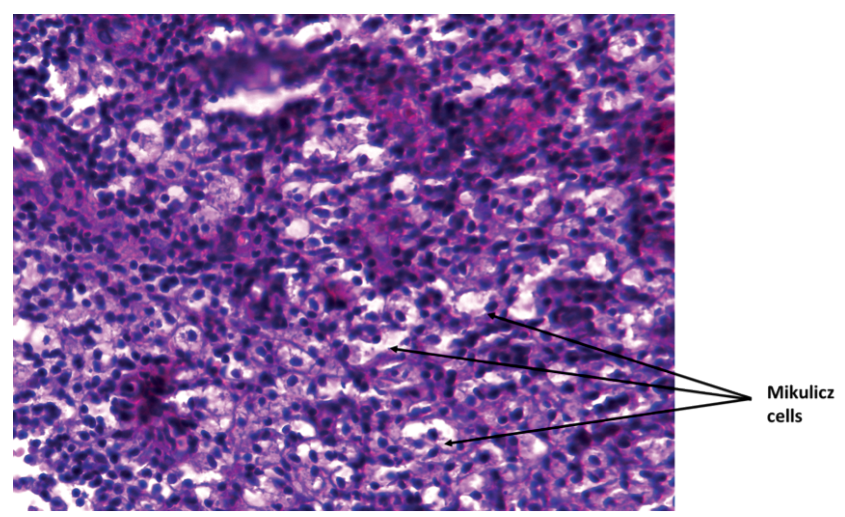

Figure 2. Histology: $\mathrm{HE} \times 400$ showing an ulcerated squamous mucous replaced by a polymorphous granulation tissue. The chorion is the seat of Mikulicz cells

film ablation was performed at 10 days and 1 month postoperatively, and there was a cicatricial retraction of the nasal cavities requiring calibration with a tamponade probe for 48 hours. Medical treatment with doxycycline ( $200 \mathrm{mg}$ daily) was also initiated for more than 4 months before surgery. It is because of the lack of effectiveness of the medical treatment, that surgery was indicated. Nine months after surgery, The patient acquired good nasal cavity permeability despite a small scar retraction (Figure 4).

\section{Case II}

The lady was 26 years old and had a track record of a caesarian section that harkens back to 2003. In 2014, she complained about a bilateral nasal obstruction that had been dragging for 9 years, coupled with bilateral epistaxis, purulent rhinorrhea and cacosmia. The examination revealed the presence of a granulomatous and crustous lesion filling the two nasal passages. Histological examination revealing rhinoscleroma twice on the

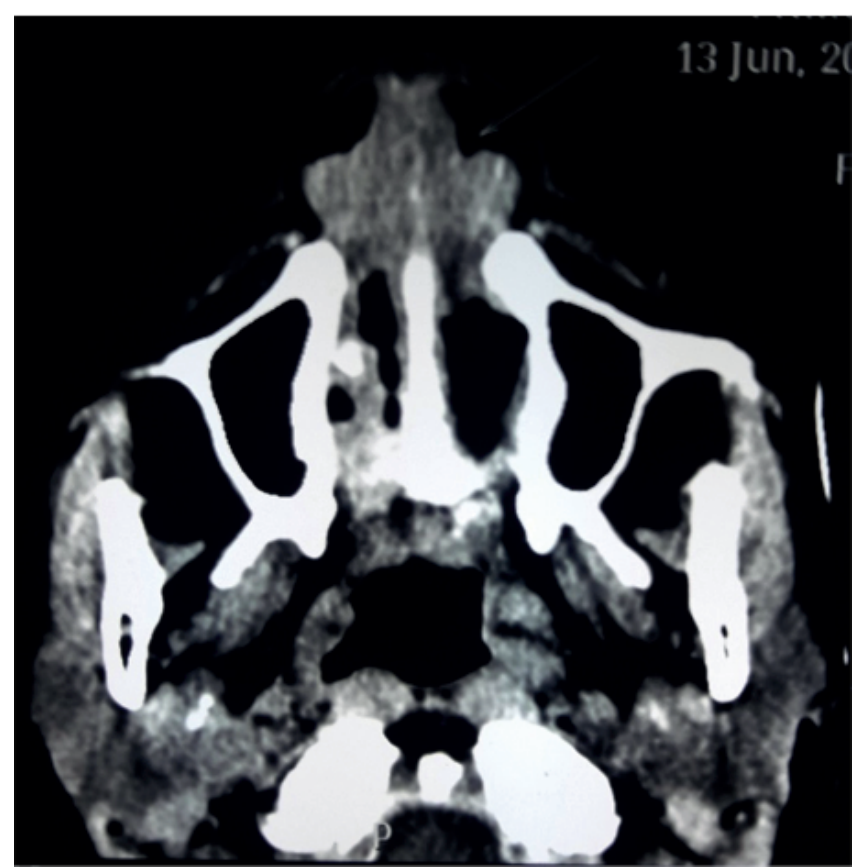

Figure 3. Tissue mass filling the nasal vestibule (case 1).

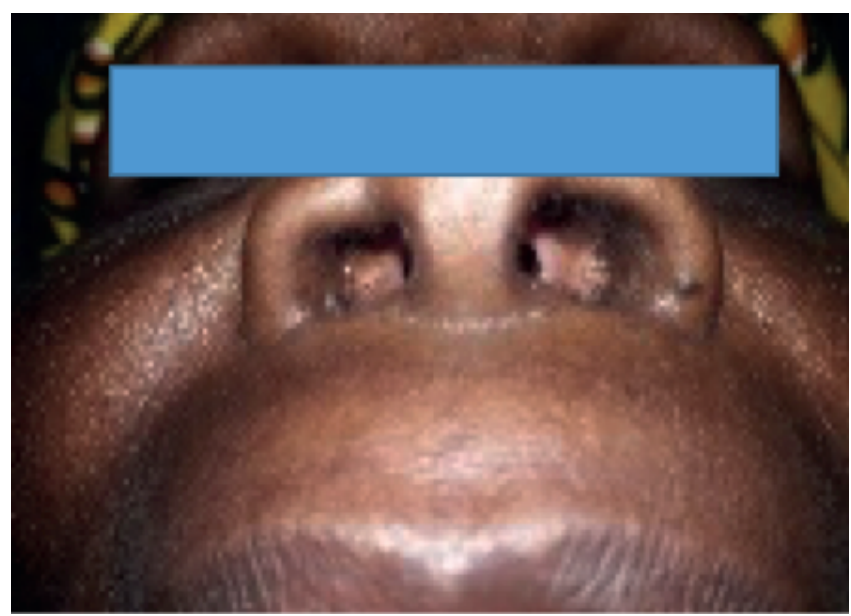

Figure 4. Cicatricial retraction of the nasal fossae.

2 biopsy fragments taken remotely. The rest of the ENT examination was normal. Computed tomography scan showed a filling of the nasal cavities in front of the head of the inferior turbinate (Figure 5). Treatment with doxycycline did not eliminate crusts. This motivated a debulking. The evolution at 5 months postoperatively was marked by a good permeability of the nasal passages which were wide.

\section{Discussion}

Von Hebra described rhinoscleroma in 1870 for the first time. Von Frisch was the first to claim the microbial etiology of the disease in 1882. He gave his name to the disease-causing bacterium (Bacillus Von Frisch). However, it was in 1887 that Mikulicz demonstrated the presence of foam cells in the scleroma tissue (Mikulicz cells) ${ }^{(1)}$. 


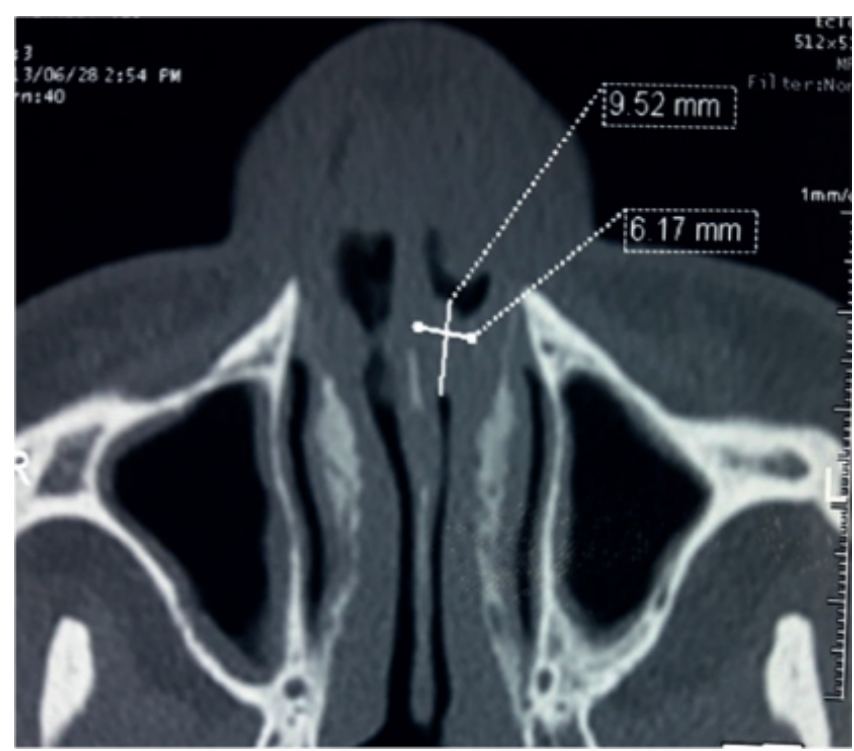

Figure 5. Tissue mass filling the nasal vestibule (case 2).

Rhinoscleroma is an endemic disease. It is prevalent in tropical Africa, the Maghreb, Asia, and Latin America. Furthermore, patients in Central Europe and Central America are also affected (2). Increasingly, new cases are reported in non-endemic areas $(3,4)$. The movement of populations from one area to another, especially to the northern countries, and people's stay in an endemic zone explain this new situation. More than 100 articles describing this condition have been found in the literature. In the majority of cases, these are clinical cases that came from all 5 continents. Women seem to be the most affected by the condition ${ }^{(1,2)}$. In contrast, some authors have reported a male predominance ${ }^{(5,6)}$.

The clinical symptomatology is summarized in 4 progressive phases ${ }^{(1)}$ :

The 1st stage or catarrhal stage: an ordinary chronic rhinitis chart with congestive nasal mucosa.

The 2 nd stage or atrophic stage. Rhinitis becomes crusty with a foul odor.

The 3rd stage or infiltration stage. There is an appearance of granulation tissue filling the nasal fossae. The attack can continue towards the air sites that will develop.

The 4th stage or scar stage. The granuloma "ages" and turns into a sclerotic mass. The facies resembles that of a rhinoceros (large, indurated nose). Nasal involvement is almost constant (95\%) $(1,2,6)$.

From this nasal colonization (which may go unnoticed), the infection can spread throughout the respiratory tract; from the nasopharynx to the bronchi. Buccopharyngeal involvement is rare and is mainly of interest to the veil, which can be amputated as a sign of Badrawy's veil. Pillars may retract causing pharyngeal ste- nosis. The oral vestibule (7) and the palate can also be affected ${ }^{(8)}$. Nasopharyngeal ${ }^{(1,2,9)}$, laryngeal ${ }^{(2,6,10,11)}$ as well as tracheal ${ }^{(4)}$ forms are rarely reported. Laryngeal involvement or laryngoscleroma is of more interest to the subglottis ${ }^{(3,6,10)}$. The sinus ${ }^{(6)}$, ganglionic ${ }^{(9)}$ and cerebral ${ }^{(1)}$ localizations by erosion of the ethmoid-screened plate are also reported.

Bacteriology can identify the germs in nasal or pharyngeal secretions, in smears or biopsy specimens. Histology provides diagnostic certainty in the presence of large histiocytes and containing Von Frish bacillus called Mikulicz cells. It may be noncontributory at an early stage ${ }^{(11)}$. Serology also generally helps with diagnosis but was not available in our laboratories ${ }^{(12)}$. Computed tomography helps to check the freedom of other airway structures and to discuss a malignant lesion. A panendoscopy is useful in low aerial locations and allows searching for a second location ${ }^{(11)}$.

The differential diagnosis can be made from other conditions such as leprosy, tuberculosis, Wegener's disease, ozena ... Leprosy is manifested by atrophic rhinitis. It causes a collapse of the pyramid that can associate with a perforation of the septum. It is caused by Hansen's bacillus ${ }^{(13)}$. The diagnosis of tuberculosis is histological with the presence of a giant cell epithelioma with central caseous necrosis ${ }^{(14)}$. Wegener's granulomatosis defines a systemic small-vessels vasculitis, characterized by frequent involvement of upper and lower respiratory tract. The presence of cytoplasmic-type ANCA with anti-proteinase 3 specificity is observed in more than $90 \%$ of Wegener's disease cases ${ }^{(15)}$. The ozena is characterized by a triad made of: open nasal fossae, the presence of crusts and cacosmia. Its etiopathogenesis remains unclear ${ }^{(16)}$.

Nasal manifestations of systemic diseases can also simulate rhioscleroma ${ }^{(17)}$. The European Rhino Research Forum organized by the European Forum for Research and education on allergic and respiratory diseases (EUFOREA) should include in its next meetings, the study of the causes of nasal obstruction in particular granulomatous lesions such as rhinoscleroma ${ }^{(18)}$.

Medical treatment is always required and allows sterilization of the infectious center. It must continue even after a possible surgical excision. There is a panel of effective molecules. The efficacy of streptomycin has been known since Miller in 1946, but exposes it to a risk of cochleovestibular toxicity that should be prevented by regular auditory control ${ }^{(1,2,6)}$. Fluoroquinolones, sulfamethoxazole-trimethoprim, cotrimoxazole and tetracycline have also been proven. Currently, the most used molecule seems to be fluoroquinolones ${ }^{(3,4,7,11,19)}$; probably because of their effectiveness associated with their least side effects. The duration of the treatment is uncodified and varies between 6 weeks and 6 months according to the authors ${ }^{(9)}$. The correction of nutritional and martial deficits falls within the framework of 
prevention. Surgery is indicated in the advanced cicatricial forms but also in case of major functional impairment (nasal obstruction, laryngo tracheal stenosis). Gestures are surgical excision $(7,8)$, debulking as in our patients or laryngotracheal stenosis cure ${ }^{(4,10)}$. Recurrence after treatment is possible ${ }^{(2,20)}$.

\section{Conclusions}

As the disease recurs, rhinoscleroma is becoming more and more a cosmopolitan occurence. The diagnosis is histological. Well-conducted medical treatment allows healing in early forms while surgery is complementary in advanced forms. The fear of a recurrence requires an extended follow-up.

\section{Acknowledgement}

None.

\section{Authorship contribution}

MN wrote the manuscript and all authors discussed the results and contributed to the final manuscript.

\section{Conflict of interest}

None declared.

\section{Ethics approval and consent to participate}

Both patients gave their consent.

\section{Consent for publication}

Not applicable.

\section{Availability of data and materials}

All data generated or analysed during this study are included in this published article.

\section{Funding}

The authors declare no source of funding.

\section{References}

1. Ennouri A, Hajri H, Mezni F El. Sclérome et rhinosclérome. Encycl Med. Chir Oto-RhinoLaryngologie. 1991; 20-380.

2. Ouoba K. le rhinosclérome : épidémiologie, clinique et thérapeutique, à propos de 51 cas observés au centre hospitalier national de Ouagadougou. Médecine d'Afrique Noire. 1997; 44 (7)

3. Gobel $Y$, Valette $G$, Delahaye $L$, et al. A case of laryngeal rhinoscleroma. Eur Ann Otorhinolaryngol Head Neck Dis. 2016; 133(3): 215

4. Bigi A, Bartolomeo M, Costes $V$, et al. Tracheal rhinoscleroma. Eur Ann Otorhinolaryngol Head Neck Dis. 2016 2016, 133(1): 51-53.

5. Boumed A, Bassi I, Adny A, et al. Le rhinosclérome: à propos de 17 cas. Annales Françaises d'Oto-Rhino-Laryngologie et de pathologie cervico-faciale. 2012; 129(4S): A100.

6. N'gattia K V, Kacouchia N, Koffi-N'quessan I, et al. Retrospective study of the rhinoscleroma about 14 cases in ENT departments of university hospitals (Côte d'Ivoire). Eur Ann Otorhinolaryngol Head Neck Dis. 2011; 128(1): 7-10.

7. Ali I, et al. Rhinoscleroma: A Case Report with Review of Literature. Arch CranOroFac Sc. 2014; 3(1):1-7.

8. Elola A, et al. Le rhinosclérome : deux obser- vations à Bobo-Dioulasso au Burkina Faso. Med Sante Trop. 2012 : $22:$ 409-411.

9. Lassikri O, et al. Rhinosclerome du cavum avec expression ganglionnaire cervicale: à propos d'un cas. Pan African Med J. 2018; 30:116,

10. Zaki Z, et al. Sclérome en ORL. La Lettre d'ORL et de chirurgie cervico-faciale. 2008; 314: 15-16.

11. Sahli M, Hemmaoui B, Errami N, et al. Localisation laryngée d'un rhinosclérome. Annales françaises d'Oto-rhino-laryngologie et de Pathologie Cervico-faciale. 2016: 133(3): 196-197

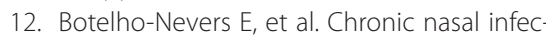
tion caused by $\mathrm{K}$. rhinoscleromatis or $\mathrm{K}$. ozaenae. Int J Infect Dis. 2007; 11: 423-429.

13. Ondzotto G, Galiba J, Kouassi B, Bamba M. Les manifestations ORL de la lèpre. Médecine et maladies infectieuses. 2003; 33: 314-317

14. Nitassi S, Nazih N, Boujemaoui M, et al. Tuberculose naso-sinusienne : à propos d'un cas. Fr ORL. $2007 ; 93: 348$

15. Karras A, Guiard E, Lévi C, Thervet E. Granulomatose avec polyangéite (maladie de Wegener). La Presse Médicale. 2012; 41(10): 1014-1023

16. Horra A, Taali L, Kadiri F. Prise en charge thérapeutique de la rhinite atrophique primitive (l'ozène): à propos de dix cas. Annales Françaises d'Oto-Rhino-Laryngologie et de pathologie cervico-faciale. 2012, 129(4S) : A100

17. Prokopakis E, et al. Nasal manifestations of systemic diseases. B-ENT. 2013; 9(3):171-84

18. Hellings PW, et al. EUFOREA Rhinology Research Forum 2016: report of the brainstorming sessions on needs and priorities in rhinitis and rhinosinusitis. Rhinology. 2017 Sep 1;55(3):202-210.

19. Kallel $\mathrm{S}$, et al. Le rhinosclérome une infection chronique rare des fosses nasales. Pan African Med J. 2018;31:247,

20. Allah K C, et al. 2012. Rhinosclérome géant. Rev Stomatol Chir Maxillofac Chir Oral. 2013;114:184-186

Moustapha Ndiaye

Faculty of Medicine

ENT department

Fann University Hospital Center

Cheikh Anta Diop University

Dakar

Senegal

Tel: +221771582148

E-mail: moustapha0905@gmail.com

ISSN: 2589-5613 / ( 2019 The Author(s). This work is licensed under a Creative Commons Attribution 4.0 International License. The images or other third party material in this article are included in the article's Creative Commons license, unless indicated otherwise in the credit line; if the material is not included under the Creative Commons license, users will need to obtain permission from the license holder to reproduce the material. To view a copy of this license, visit http://creativecommons.org/licenses/by/4.0/ 